\title{
Dental Sealants: Knowledge, Value, Opinion, and Practice among Dental Professionals of Bathinda City, India
}

\author{
Kailash Asawa, ${ }^{1}$ Vivek V. Gupta, ${ }^{1}$ Mridula Tak, ${ }^{1}$ Ramesh Nagarajappa, ${ }^{2}$ \\ Pulkit Chaturvedi, ${ }^{1}$ Salil Bapat, ${ }^{1}$ Prashant Mishra, ${ }^{3}$ and Santanu Sen Roy ${ }^{4}$ \\ ${ }^{1}$ Department of Public Health Dentistry, Pacific Dental College and Hospital, Debari, Udaipur, Rajasthan, India \\ ${ }^{2}$ Department of Public Health Dentistry, Rama Dental College and Hospital, Kanpur, Uttar Pradesh, India \\ ${ }^{3}$ Department of Public Health Dentistry, Sri Aurobindo Institute of Dental Sciences, Indore, Madhya Pradesh, India \\ ${ }^{4}$ Department of Public Health Dentistry, Guru Nanak Dental College \& Hospital, Kolkata, West Bengal, India
}

Correspondence should be addressed to Kailash Asawa; kailashasawaudr@yahoo.com

Received 2 January 2014; Revised 12 March 2014; Accepted 18 March 2014; Published 10 April 2014

Academic Editor: Masaru Shimada

Copyright (c) 2014 Kailash Asawa et al. This is an open access article distributed under the Creative Commons Attribution License, which permits unrestricted use, distribution, and reproduction in any medium, provided the original work is properly cited.

\begin{abstract}
Objective. The purpose of the study was to assess the knowledge, value, opinion, and practice regarding use of dental sealants among private dental practitioners in Bathinda City, Punjab, India. Materials and Methods. A cross-sectional survey was conducted among all private dental practitioners in Bathinda City, Punjab. A self-administered structured questionnaire consisting of 28 items was used to assess their knowledge, value, opinion, and practice regarding dental sealants. One-way analysis of variance, independent sample $t$-test, and multivariate regression analysis were utilized for statistical analysis. Confidence level and level of significance were set at $95 \%$ and 5\%, respectively. Results. The mean scores for knowledge, value, opinion, and practice were 41.8 $\pm 3.7,18.7 \pm 2.8$, $18.1 \pm 1.4$, and $12.9 \pm 2.3$, respectively. Analysis revealed that qualification was statistically significant among all dependent variables $(P \leq 0.05)$; work experience was significantly associated with both knowledge and opinion means scores $(P \leq 0.05)$. Conclusion. The results suggest that dental practitioners had sufficient knowledge about dental sealants. They also acknowledge the importance of use of dental sealants. Practice of dental sealants in clinics was found adequate but they were not following the specific guidelines and standardized procedures.
\end{abstract}

\section{Introduction}

Dental caries is an important public health problem and it is the most prevalent oral disease among children. This disease not only causes damage to the tooth but is also responsible for several morbid conditions of the oral cavity and other systems of the body [1]. The global distribution of dental caries has shown distinctive variations [2]. The scenario in India also shows similarities with other developing countries. A very extensive and comprehensive National Health Survey conducted in 2004 throughout India has shown dental caries prevalence of $51.9 \%$ in 5-year-old children, $53.8 \%$ in 12 -yearold children, and $63.1 \%$ in 15 -year-old teenagers [3].

A survey conducted in 7 districts (Arunachal Pradesh, Delhi, Maharashtra, Puducherry, Rajasthan, Orissa, and Uttar Pradesh), covering 3200 subjects from each site, showed a very high prevalence of dental caries in Puducherry (71.5\%), while Orissa was found to have the least prevalence (23\%) among the 12-year-old age group [4]. Apart from these, the anecdotal prevalence has been obtained at various locations in Punjab. In the year 2013, the prevalence of dental caries in Ludhiana was found to be as high as $81.4 \%$ in the 12 -yearold age group and $86.2 \%$ among 15 -year-old age group [5]. In a similar study among 5- and 12-year-old schoolchildren of Chandigarh the prevalence of dental caries was found to be $48.3 \%$ and $30.5 \%$ in the year 2012 [6].

Pits and fissures are the most caries-vulnerable sites of teeth; the percentage of total caries attributable to occlusal surfaces compared with smooth surfaces has increased [7]. It was generally accepted that nearly all molar occlusal surfaces would eventually become carious [8-10]. As reviewed by Eklund and Ismail, during the 1950s, 1960s, and 1970s, 70\% 
of all molar occlusal surfaces became carious within 10 years of emergence into the oral cavity [11].

Buonocore's classic study of 1955 marked the start of a major revolution in the clinical practice of dentistry [12]. The first clinical benefit from Buonocore's work was the introduction of the first dental pit and fissure sealant, NuvaSeal (L.D. Caulk) in February 1971 [13]. The term pit and fissure sealant is used to describe a material that is introduced into the occlusal pits and fissures of caries-susceptible teeth, thus forming a micromechanically bonded, protective layer cutting access of caries-producing bacteria from their source of nutrients [14].

Strong evidence shows that sealants are effective in preventing caries $[15,16]$. Over the last few years more than 11 guidelines and systematic reviews have recommended pit and fissure sealant use for at-risk populations [17-19]. However, more than 30 years after the introduction of pit and fissure sealant to the dental market place, the profession has not embraced the procedure to the extent that available scientific data would expect [13]. Studies from USA [20], Greece [21], Sweden [22], and Scotland [23] all indicate that sealants are underutilized. Hence, the objective of the present crosssectional study was to assess the knowledge, value, opinion, and practice (KOVP) regarding dental sealants among dental professionals of Bathinda City, Punjab, India.

\section{Materials and Methods}

2.1. Study Design and Population. A descriptive cross-sectional study was conducted among dental professionals of Bathinda City, Punjab, India, in the month of July 2013. Study population consisted of all the private dental practitioners of Bathinda City.

2.2. Ethical Approval. The study protocol was reviewed by the Ethical Committee of Pacific Dental College and Hospital and was granted ethical clearance.

2.3. Pretesting of Questionnaire. A self-administered structured questionnaire was developed and tested among a convenience sample of 10 dentists, who were interviewed to gain feedback on the overall acceptability of the questionnaire in terms of length and language clarity. Based on their feedback, the questionnaire did not require any corrections. Cronbach's coefficient was found to be 0.80 , which showed an internal reliability of the questionnaire. Mean content validity ratio (CVR) was calculated as 0.87 based on the opinions expressed by a panel of five academicians. Face validity was also assessed and it was observed that $92 \%$ of the participants found the questionnaire to be easy.

2.4. Questionnaire. The questionnaire, designed to obtain dentists' knowledge, opinion, value, and practice towards dental sealants, consisted of five sections. Section I solicited general demographic details and information on professional background. The dentists involved in active patient care were asked about years of experience in a dental clinic. Section II integrated 11 questions to collect information about knowledge regarding dental sealants. Section III comprised of 5 questions which aimed to assess the value regarding dental sealants. Section IV contained 5 questions regarding opinion about dental sealants. Section V consisted of 7 questions regarding dental sealants practice. The participant's responses for Sections II, III, and IV were ranked according to how much they agreed with each statement that was based on the 5 point Likert scale with alternatives: strongly disagree, disagree, neutral, agree, and strongly agree. For Section V the participant's responses were recorded as never, sometimes, and always.

2.5. Methodology. The investigator collected the list of private practicing dentists from local sources (local IDA branch and telephone directory). Among a total of 166 dental practitioners, a pilot study was conducted on 10 dental practitioners. These were later excluded from the main study and the final sample size was 156 practitioners. On the predecided days, the investigator visited the private clinics, according to area of distribution, to get the questionnaire filled. Questionnaires were distributed among all dentists $(n=156)$ who were requested to fill in the written informed consent form and were asked to rate each item of the questionnaire choosing the most appropriate response. The investigator revisited the clinics after 3 days to collect the filled questionnaires. Hundred percent response rate was achieved by 2-3 followups.

2.6. Statistical Analysis. Completed questionnaires were coded and spreadsheets were created for data entry. The data was analyzed using SPSS 15 (SPSS Inc., Chicago, IL, USA) Windows software program.

Responses to all items of the Sections II, III, and IV were coded from 1-5 (strongly disagree to strongly agree). Responses in Section V were coded from 1-3 (never, sometimes, and always). Several items like question 9 in Section II, question 1, 2, and 3 in Section III, and questions 1, 2, and 5 in Section IV were recoded to ensure that a high score indicated a positive knowledge, value, opinion, and practice and a low score indicated a negative knowledge, value, opinion, and practice. Mean knowledge, opinion, value, and practice scores and standard deviation were calculated. For frequency distribution, strongly disagree and disagree responses were combined into one category (disagree) and similarly agree and strongly agree responses (agree). Descriptive statistics were used to summarize the demographic information and the survey data was analyzed using the student's $t$ test and one-way ANOVA with post hoc Bonferroni test. Multivariate logistic regression analysis models were used to check relation between independent (age, sex, qualification, and work experience) and dependent variables (knowledge, value, opinion, and practice). Confidence level and level of significance were fixed at $95 \%$ and $5 \%$, respectively.

\section{Results}

In Table 1 a total of 156 dentists with the mean age (in years) of $32.9 \pm 5.3$ participated in the survey. Demographic data showed that the majority of the respondents were graduates 
TABLE 1: Demographic characteristics of dentists of study population.

\begin{tabular}{lc}
\hline Sample characteristics & Frequency (\%) \\
\hline Age (in years) & $101(64.7)$ \\
$25-34$ & $43(27.6)$ \\
$35-45$ & $12(7.7)$ \\
$>45$ & \\
Sex & $92(59)$ \\
$\quad$ Male & $64(41)$ \\
Female & \\
Qualification & $54(34.6)$ \\
MDS & $102(65.4)$ \\
BDS & \\
Years of experience (in years) & $83(53.2)$ \\
$<5$ & $36(23.1)$ \\
$5-10$ & $37(23.7)$ \\
$>10$ & $156(100)$ \\
\hline Total &
\end{tabular}

(65.4\%), males (59\%), and in the age group of 25-35 years (71.2\%). 53.2\% of the dental health professional had $<5$ years of work experience.

In Table 2 the mean knowledge, value, opinion, and practice scores of the study population were evident as $41.8 \pm$ $3.7,18.7 \pm 2.8,18.1 \pm 1.4$, and $12.9 \pm 2.3$, respectively. Postgraduates had significantly greater knowledge and practice than graduates. Mean scores for postgraduates and graduates were $44.5 \pm 2.9,39.7 \pm 2.9(P=0.000)$ and $13.7 \pm 0.4$, $12.5 \pm 2.7(P=0.01)$, respectively. When post hoc Bonferroni test was applied, mean knowledge score among those who had less than 5 years of experience $(42.3 \pm 4.2)$ was found to be significantly greater than among those who had more than 10 years of experience $(40.7 \pm 3.5)(P=0.001)$.

Table 3 depicted that $84.6 \%$ of the dentists showed familiarity with the sealant placement technique and $84.7 \%$ believed that sealants should be reviewed after placement. $62.8 \%$ of the dentists thought that materials used for the placement of sealants are very expensive and their effect is very short lived. $80.2 \%$ of the dentists found difficulty in justifying the cost of sealants to the parents and $78.8 \%$ of the dental professionals had an opinion that it is necessary to promote the use of sealants among dentists and dental educators.

In Table 4 multivariate logistic regression analysis revealed that knowledge had a significant association with qualification and years of work experience [OR $=2.5(0.4-$ $5.0), \mathrm{OR}=0.9(0.6-5.1)]$ and practice showed a significant statistical association with qualification $[\mathrm{OR}=0.8(0.2-1.9)]$, respectively.

\section{Discussion}

The present study was conducted among 156 dental practitioners of Bathinda City, Punjab, to assess their dental sealants knowledge, value, opinion, and practice. To the best of our knowledge, this is the first study to examine the knowledge, value, opinion, and practice of dental sealants among Indian dental practitioners.

In the present study, knowledge, value, and opinion on dental sealants was found to be associated with years of work experience and qualification. Multivariate analysis revealed that knowledge showed significant association with qualification and years of work experience, while practice showed significant association with qualification only. Dental professionals who had more than 10 years of work experience had less knowledge than those who had 5-10 or less than 5 years of work experience and this is in accordance with a study conducted by San Martin et al. [24] among Spanish dentists. This might be due to lack of frequent practice of dental sealants in their clinical practice. The study also revealed that dentists with postgraduate qualifications showed a significantly greater mean knowledge and practice score than those with undergraduate qualifications. This might be due to their more familiarity and use of dental sealants when they were perusing their postgraduation degree in pediatric dentistry, restorative dentistry, and preventive dentistry [21].

In the present study, $52 \%$ of dentists responded that it was difficult to justify the cost of sealants to parents. This finding might be correlated to the study conducted by Albert et al. [25] who stated that pit and fissure sealant treatment plans offered by American dentists are rejected by $55.7 \%$ of the parents most frequently because of the cost factor. In contrast San Martin et al. [24] reported lesser proportion of Spanish dentists $(34.6 \%)$ portraying difficulty in justifying the cost of sealants to the parents. Moreover in our study, around $62.8 \%$ of dental professionals agreed that materials used for placement of sealants were very expensive which is in contrast to the findings of San Martin et al. [24] among Spanish dentists (13.1\%). This might be due to the fact that the National Health System at Spain provides care for all children, independent of parent income [24].

In contrast to $31.6 \%$ of Spanish dentists [24], 59\% of the dental professionals in the present study depicted difficulty in explaining to patients what dental sealants are. This might be due to higher literacy rate and awareness among Spanish population regarding dental sealants.

In the present study, $35.9 \%$ of the study subjects agreed about the adverse effects of dental sealant and $35.9 \%$ showed a neutral response which shows considerable doubt in the minds of many dentists about the safety of pit and fissure sealants. No reports of adverse health effects have been attributed to the leached components of dental sealants. It is therefore questionable whether these materials indeed are leached out of dental sealants in quantities that can pose a health hazard [26].

$84.6 \%$ of dental practitioners in our study were found to be familiar with sealant placement technique and $83.9 \%$ believed that proper technique of sealant application is fundamental to the success of the treatment. $87.2 \%$ of them were following proper isolation and acid etching techniques but contrary to this around $84.6 \%$ of them responded that they were not following specific guidelines. This may be attributed to the belief of $69.8 \%$ dentists that the technique takes time to do correctly [27]. 
TABLE 2: Association of mean knowledge, value, opinion, and practice score with independent variables.

\begin{tabular}{|c|c|c|c|c|c|c|c|c|}
\hline \multirow{2}{*}{ Variables } & \multicolumn{2}{|c|}{ Knowledge } & \multicolumn{2}{|c|}{ Value } & \multicolumn{2}{|c|}{ Opinion } & \multicolumn{2}{|c|}{ Practice } \\
\hline & Mean \pm SD & $P$ value & Mean \pm SD & $P$ value & Mean \pm SD & $P$ value & Mean \pm SD & $P$ value \\
\hline \multicolumn{9}{|l|}{ Sex } \\
\hline Male & $41.6 \pm 3.7$ & \multirow{2}{*}{0.47} & $17.4 \pm 2.2$ & \multirow{2}{*}{0.88} & $18.3 \pm 2.3$ & \multirow{2}{*}{0.07} & $12.9 \pm 2.2$ & \multirow{2}{*}{0.76} \\
\hline Female & $41.1 \pm 3.6$ & & $18.3 \pm 1.9$ & & $18.1 \pm 1.9$ & & $12.9 \pm 2.5$ & \\
\hline \multicolumn{9}{|c|}{ Age (in years) } \\
\hline 25-34 & $40.9 \pm 3.7$ & \multirow{3}{*}{0.06} & $17.6 \pm 2.1$ & \multirow{3}{*}{0.96} & $18.1 \pm 2.1$ & \multirow{3}{*}{0.11} & $12.8 \pm 2.5$ & \multirow{3}{*}{0.42} \\
\hline $35-44$ & $42.3 \pm 3.5$ & & $17.7 \pm 2.0$ & & $18.7 \pm 2.0$ & & $13.3 \pm 1.9$ & \\
\hline$\geq 45$ & $42.4 \pm 3.8$ & & $17.7 \pm 2.3$ & & $19.1 \pm 2.9$ & & $13.3 \pm 2.0$ & \\
\hline \multicolumn{9}{|c|}{ Qualification } \\
\hline MDS & $44.5 \pm 2.9$ & \multirow{2}{*}{$0.00^{*}$} & $18.2 \pm 1.9$ & \multirow{2}{*}{0.07} & $20.2 \pm 1.8$ & \multirow{2}{*}{0.08} & $13.7 \pm 0.4$ & \multirow{2}{*}{$0.01^{*}$} \\
\hline BDS & $39.7 \pm 2.9$ & & $17.7 \pm 2.0$ & & $19.3 \pm 1.6$ & & $12.5 \pm 2.7$ & \\
\hline \multicolumn{9}{|c|}{ Work experience (in years) } \\
\hline$<5$ & $42.3 \pm 4.2^{\mathrm{a}}$ & \multirow{3}{*}{$0.04^{*}$} & $17.7 \pm 2.0$ & \multirow{3}{*}{0.82} & $18.9 \pm 2.0$ & \multirow{3}{*}{0.78} & $12.8 \pm 2.5$ & \multirow{3}{*}{0.37} \\
\hline $5-10$ & $42.1 \pm 3.3$ & & $17.8 \pm 2.2$ & & $18.4 \pm 1.9$ & & $12.9 \pm 2.5$ & \\
\hline$>10$ & $40.7 \pm 3.5^{\mathrm{a}}$ & & $17.5 \pm 2.1$ & & $17.8 \pm 2.6$ & & $13.4 \pm 1.7$ & \\
\hline Total & $41.8 \pm 3.7$ & & $18.7 \pm 2.8$ & & $18.1 \pm 1.4$ & & $12.9 \pm 2.3$ & \\
\hline
\end{tabular}

Statistical tests applied: $t$ test, one way ANOVA.

* indicates statistically significant difference at $P \leq 0.05$.

Post hoc Bonferroni test: Groups with same letter (a) suprascripted showed statistically significant difference.

$62.8 \%$ of practitioners in our study responded that they do not use sealants as a preventive method very often because its effect is short lived and this may be attributed to the knowledge of the practitioners that the sealants wear off easily. Contrary to this $84.7 \%$ of the dentists believed that if at all they place sealants it should be reviewed periodically. High retention rates of sealants were achieved when recall was incorporated [28].

In our study, $78.8 \%$ of respondents agreed about the effectiveness of resin sealants over glass ionomer sealants [29]. The resin-based sealant is superior not only in terms of retention, but also in caries prevention [30].

Out of 156 dental professionals, approximately $80 \%$ were avoiding dental sealants for the possibility of sealing over caries. In contrast, [31] noted that a limited number of cultivable organisms persist in some lesions which do not appear capable of continuing the destruction of tooth structure.

$78.8 \%$ of participants in this study found it necessary to promote the use of dental sealants. Professional organizations should take a more active role in promoting sealant use among dentists [32].

In the present study, significantly greater proportion (85.3\%) of the participants found that better caries prevention can be attained when sealants were used along with fluorides. Additional caries-preventive benefits were observed when pit and fissure sealants were applied along with fluoride therapyx [33]. It has been recognized that the addition of fluoride to a sealant or perhaps to the enamel prior to sealant application could have the potential benefit of additional caries protection, without compromising the properties of the sealant [34].
In case of partial or complete loss of sealants, $85.9 \%$ of dentists were not reapplying regardless of sealant retention; caries experience was low under partially retained or missing sealants and completely retained sealants $[35,36]$.

The present study surveyed all the private dental practitioners of Bathinda City with a $100 \%$ response rate. Moreover, the self-administered questionnaire used in the study was previously calibrated and validated for the present study population.

The assessment of knowledge, value, opinion, and practice was based on dental practitioners self-report. Questionnaires were administered among all the dental practitioners in the city to provide a more comfortable environment for the participants in which to answer the questions. Moreover, participants were assured that their responses would be solely used for this research. Limitations of the present study are that we are not sure how truthfully and thoughtfully the respondents answered the questionnaire and level of subjectivity is not acknowledged in the present study.

\section{Conclusion}

The present study concluded that dental practitioners had sufficient knowledge about dental sealants. They also acknowledge the importance of use of dental sealants. Practice of dental sealants in clinics was found adequate but they were not following the specific guidelines and standardized procedures. To overcome this, professional and government bodies should create clear strategies for enhancing and 
TABLE 3: Frequency of responses regarding knowledge, value, opinion, and practice.

\begin{tabular}{|c|c|c|c|}
\hline & Disagree & Neutral & Agree \\
\hline \multicolumn{4}{|l|}{ Knowledge } \\
\hline I think that the effectiveness of fissure sealants is supported by strong scientific evidence & 0 & $35(22.4)$ & $121(77.6)$ \\
\hline There is scientific evidence for the restorative use of dental sealants & $2(1.2)$ & $41(26.3)$ & $113(72.5)$ \\
\hline I am familiar with the technique of placing dental sealants & $20(12.7)$ & $4(2.6)$ & $132(84.7)$ \\
\hline I believe that fissure sealants should be reviewed after placement & $6(3.8)$ & $18(11.7)$ & $132(84.7)$ \\
\hline I understand the instructions for placing sealants & $7(4.5)$ & $16(10.3)$ & $133(85.2)$ \\
\hline I think that sealants should only be used on newly erupted teeth & $31(19.9)$ & $44(28.2)$ & $81(51.9)$ \\
\hline I think that sealants wear out easily & $29(18.6)$ & $27(17.3)$ & $100(64.1)$ \\
\hline I believe that you must perform a caries risk assessment to prevent overtreatment & 0 & $41(26.3)$ & $115(73.7)$ \\
\hline Pit and fissure sealants have adverse effects & $44(28.2)$ & $56(35.9)$ & $56(35.9)$ \\
\hline I believe the technique of applying a sealant is the most important aspect to the success of the treatment & it $1(0.6)$ & $24(15.4)$ & $131(83.9)$ \\
\hline I agree that resin sealants are more effective than glass ionomer sealant & 0 & $33(21.2)$ & $123(78.8)$ \\
\hline \multicolumn{4}{|l|}{ Value } \\
\hline I think this technique takes time to do correctly & $4(2.5)$ & $43(27.6)$ & $109(69.8)$ \\
\hline The materials that are used for the placement of sealants are very expensive & $46(29.5)$ & $12(7.7)$ & $98(62.8)$ \\
\hline I do not use sealants very often as a preventive method because its effect is short lived & $35(22.4)$ & $23(14.7)$ & $98(62.8)$ \\
\hline Fissure sealants are used less than they should be & $14(9.0)$ & $19(12.2)$ & $123(78.8)$ \\
\hline The dental staff at my clinic/work place communicates importance of using sealants to the patients & $3(1.9)$ & $30(19.2)$ & $123(78.8)$ \\
\hline \multicolumn{4}{|l|}{ Opinion } \\
\hline It is difficult to explain to patients what dental sealants are & $21(13.4)$ & $41(26.3)$ & $94(60.3)$ \\
\hline It is difficult to justify the cost of sealants to parents & $21(13.4)$ & $10(6.4)$ & $125(80.2)$ \\
\hline I think my patients understand the benefits of using sealants & $1(0.6)$ & $29(18.6)$ & $126(80.8)$ \\
\hline It is necessary to promote the use of sealants amongst dentists and dental educators & 0 & $33(21.2)$ & $123(78.8)$ \\
\hline \multirow[t]{2}{*}{ I use dental sealant because it is easy to apply and patients find it comfortable } & $2(1.2)$ & $59(37.9)$ & $95(60.9)$ \\
\hline & Never & Sometimes & Always \\
\hline \multicolumn{4}{|l|}{ Practice } \\
\hline Do not use due to possibility of sealing over caries & $24(15.4)$ & $12(7.7)$ & $120(76.9)$ \\
\hline Use as restorative material to restore incipient caries & $6(3.8)$ & $18(11.5)$ & $132(84.6)$ \\
\hline Use along with fluorides & $7(4.5)$ & $16(10.3)$ & $133(85.3)$ \\
\hline Do not reapply in case of partial or complete loss & 0 & $22(14.1)$ & $134(85.9)$ \\
\hline Proper isolation & 0 & $20(12.8)$ & $136(87.2)$ \\
\hline Proper acid etching & 0 & $20(12.8)$ & $136(87.2)$ \\
\hline Not following specific guidelines & $5(3.2)$ & $19(12.18)$ & $132(84.6)$ \\
\hline
\end{tabular}

TABLe 4: Multiple logistic regression odd ratios (95\% CI) for knowledge, value, opinion, and practice score as dependent variable among dentists.

\begin{tabular}{lcccc}
\hline Variables & Age $(<45 />45$ years $)$ & Sex $($ male/female $)$ & Qualification $(B D S / M D S)$ & Work experience $(<10 />10$ years $)$ \\
\hline Knowledge & $1.8(0.5-7.1)$ & $0.7(0.1-3.7)$ & $2.5(0.4-5.0)^{*}$ & $0.9(0.6-5.1)^{*}$ \\
Value & $1.3(0.6-2.9)$ & $1.0(0.4-2.7)$ & $3.7(1.8-7.6)$ & $1.1(0.5-3.3)$ \\
Opinion & $1.6(0.3-7.9)$ & $0.6(0.1-4.8)$ & $0.2(0.0-1.5)$ & $2.6(0.3-4.9)$ \\
Practice & $1.2(0.4-2.2)$ & $0.2(0.1-1.9)$ & $0.8(0.2-1.9)^{*}$ & $4.4(0.7-6.2)$ \\
\hline
\end{tabular}

Italicized category is taken as reference group.

improving dental practitioner's knowledge and make them confident on suggesting and using sealants. This study opens new vista for more detailed research among other dental practitioners in other parts of the country.

\section{Conflict of Interests}

The authors declare that there is no conflict of interests regarding the publication of this paper. 


\section{Acknowledgment}

The authors would like to thank the study participants for their participation and kind cooperation throughout the study.

\section{References}

[1] M. Chakraborty, J. B. Saha, R. N. Bhattacharya, A. Roy, and R. Ram, "Epidemiological correlates of dental caries in an urban slum of West Bengal," Indian Journal of Public Health, vol. 41, no. 2, pp. 56-67, 1997.

[2] V. Baelum, W. Van Palenstein Helderman, A. Hugoson, R. Yee, and O. Fejerskov, "A global perspective on changes in the burden of caries and periodontitis: implications for dentistry," Journal of Oral Rehabilitation, vol. 34, no. 12, pp. 872-906, 2007.

[3] National Oral Health Survey and Fluoride Mapping, "An Epidemiological Study of Oral Health Problems and Estimation of Fluoride Levels in Drinking Water," Dental Council of India, New Delhi, India, vol. 32, pp. 67-78, 2004.

[4] A Report of the Multi Centric Study, Ministry of Health and Family Welfare, Government of India and WHO collaborative Program, 2007.

[5] V. Munjal, A. Gupta, P. Kaur, and R. Garewal, "Dental caries prevalence and treatment needs in 12 and 15-year-old school children of Ludhiana city," Indian Journal of Oral Sciences, vol. 4, no. 1, pp. 27-30, 2013.

[6] K. R. Sohi, S. R. Gambhir, K. L. Veeresha, K. A. Randhawa, and G. Singh, "Assessment of prevalence of dental caries among 5 and 12-year-old schoolchildren in Chandigarh (U.T.), India," Archives of Oral Research, vol. 8, no. 1, pp. 39-45, 2012.

[7] R. J. Feigal and K. J. Donly, "The use of pit and fissure sealants," Pediatric Dentistry, vol. 28, no. 2, pp. 143-150, 2006.

[8] T. Hyatt, "Prophylactic odontotomy: the cutting into the tooth for the prevention of disease," Dental Cosmos, vol. 65, pp. 234241, 1923.

[9] J. W. Knutson, H. Klein, and C. E. Palmer, "Studies on dental caries. VIII. Relative incidence of caries in the different permanent teeth," Journal of the American Dental Association, vol. 25, pp. 1923-1934, 1938.

[10] J. P. Carlos and A. M. Gittelsohn, "Longitudinal studies of the natural history of caries-II. A life-table study of caries incidence in the permanent teeth," Archives of Oral Biology, vol. 10, no. 5, pp. 739-751, 1965.

[11] S. A. Eklund and A. I. Ismail, "Time of development of occlusal and proximal lesions: implications for fissure sealants," Journal of Public Health Dentistry, vol. 46, no. 2, pp. 114-121, 1986.

[12] M. G. Buonocore, "A simple method of increasing the adhesion of acrylic filling materials to enamel surfaces," Journal of Dental Research, vol. 34, no. 6, pp. 849-853, 1955.

[13] I. P. Wilson, "Preventive dentistry," Dental Digest, vol. 1, pp. 70$72,1895$.

[14] R. J. Simonsen, "Pit and fissure sealants," in Clinical Applications of the Acid Etch Technique, pp. 19-42, Quintessence Publishing Company, Chicago, Ill, USA, 1st edition, 1978.

[15] B. I. Truman, B. F. Gooch, I. Sulemana et al., "Reviews of evidence on interventions to prevent dental caries, oral and pharyngeal cancers, and sports-related craniofacial injuries," American Journal of Preventive Medicine, vol. 23, no. 1, supplement, pp. 21-54, 2002.
[16] A. Ahovuo-Saloranta, A. Hiiri, A. Nordblad, H. Worthington, and M. Mäkelä, "Pit and fissure sealants for preventing dental decay in the permanent teeth of children and adolescents," Cochrane Database of Systematic Reviews, no. 3, Article ID CD001830, 2004.

[17] S. Mickenautsch and V. Yengopal, "Caries-preventive effect of glass ionomer and resin-based fissure sealants on permanent teeth: an update of systematic review evidence," BMC Research Notes, vol. 4, article 22, 2011.

[18] A. Hiiri, A. Ahovuo-Saloranta, A. Nordblad, and M. Mäkelä, "Pit and fissure sealants versus fluoride varnishes for preventing dental decay in children and adolescents," Cochrane Database of Systematic Reviews, no. 4, Article ID CD003067, 2006.

[19] V. Yengopal and S. Mickenautsch, "Resin-modified glassionomer cements versus resin-based materials as fissure sealants: a meta-analysis of clinical trials," European Archives of Paediatric Dentistry, vol. 11, no. 1, pp. 18-25, 2010.

[20] M. Tellez, S. L. Gray, S. Gray, S. Lim, and A. I. Ismail, "Sealants and dental caries: dentists' perspectives on evidence-based recommendations," Journal of the American Dental Association, vol. 142, no. 9, pp. 1033-1040, 2011.

[21] M. Michalaki, M. Sifakaki, C. J. Oulis, and N. A. Lygidakis, "Attitudes, knowledge and utilization of fissure sealants among Greek dentists: a national survey," European Archives of Paediatric Dentistry, vol. 11, no. 6, pp. 287-293, 2010.

[22] C. J. Oulis, E. D. Berdouses, E. Mamai-Homata, and A. Polychronopoulou, "Prevalence of sealants in relation to dental caries on the permanent molars of 12 and 15-year-old Greek adolescents. A national pathfinder survey," BMC Public Health, vol. 11, article 100, 2011.

[23] R. Sarmadi, L. Gahnberg, and P. Gabre, “Clinicians' preventive strategies for children and adolescents identified as at high risk of developing caries," International Journal of Paediatric Dentistry, vol. 21, no. 3, pp. 167-174, 2011.

[24] L. San Martin, A. Castaño, M. Bravo, M. Tavares, R. Niederman, and E. O. Ogunbodede, "Dental sealant knowledge, opinion, value and practice of Spanish dentists," BMC Oral Health, vol. 13, no. 12, pp. 1-8, 2013.

[25] D. A. Albert, K. P. Ahluwalia, E. Schooley, and D. Sadowsky, "Socioeconomic factors affecting sealant placement by dentists in a national insurance plan," in Proceedings of the 128th Annual Meeting of American Public Health Association (APHA '00), Abstract no. 14570, pp. 12-16, 2000.

[26] A. Manabe, S. Kaneko, S. Numazawa et al., "Detection of bisphenol-a in dental materials by gas chromatography-mass spectrometry," Dental Materials Journal, vol. 19, no. 1, pp. 75$86,2000$.

[27] R. J. Simonsen, "Pit and fissure sealant: review of the literature," Pediatric Dentistry, vol. 24, no. 5, pp. 393-414, 2002.

[28] E. Jodkowska, "Efficacy of pit and fissure sealing-long-term clinical observations," Quintessence International, vol. 39, no. 7, pp. 593-602, 2008.

[29] M. Raadal, A. B. Utkilen, and O. L. Nilsen, "Fissure sealing with a light-cured resin-reinforced glass-ionomer cement (Vitrebond) compared with a resin sealant," International Journal of Paediatric Dentistry, vol. 6, no. 4, pp. 235-239, 1996.

[30] H. Forss and E. Halme, "Retention of a glass ionomer cement and a resin-based fissure sealant and effect on carious outcome after 7 years," Community Dentistry and Oral Epidemiology, vol. 26, no. 1, pp. 21-25, 1998.

[31] R. E. Going, W. J. Loesche, D. A. Grainger, and S. A. Syed, “The viability of microorganisms in carious lesions five years after 
covering with a fissure sealant," The Journal of the American Dental Association, vol. 97, no. 3, pp. 455-462, 1978.

[32] L. Cohen, A. LaBelle, and E. Romberg, "The use of pit and fissure sealants in private practice: a national survey," Journal of Public Health Dentistry, vol. 48, no. 1, pp. 26-35, 1988.

[33] R. H. Selwitz, R. Nowjack-Raymer, W. S. Driscoll, and S. H. $\mathrm{Li}$, "Evaluation after 4 years of the combined use of fluoride," Pediatric Dentistry, vol. 24, no. 5, 2002.

[34] M. L. Swartz, R. W. Phillips, R. D. Norman, S. Elliason, B. F. Rhodes, and H. E. Clark, "Addition of fluoride to pit and fissure sealants-a feasibility study," Journal of Dental Research, vol. 55, no. 5, pp. 757-771, 1976.

[35] G. T. Charbeneau, J. B. Dennison, and G. Ryge, "A filled pit and fissure sealant: 18-month results," The Journal of the American Dental Association, vol. 95, no. 2, pp. 299-306, 1977.

[36] L. B. Messer, H. Calache, and M. V. Morgan, "The retention of pit and fissure sealants placed in primary school children by Dental Health Services, Victoria," Australian Dental Journal, vol. 42, no. 4, pp. 233-239, 1997. 


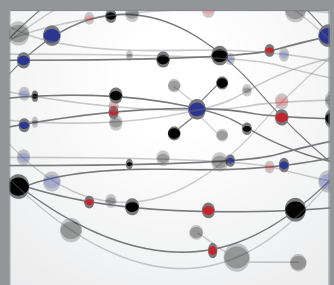

The Scientific World Journal
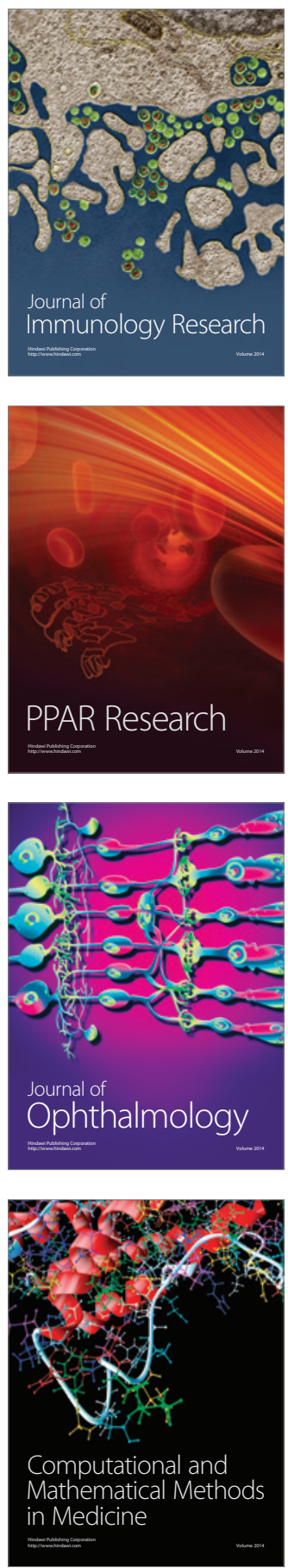

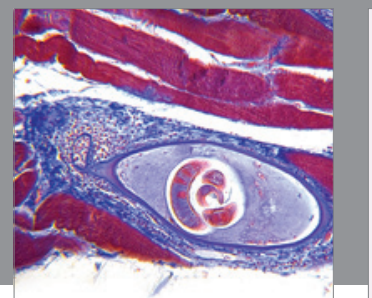

Gastroenterology

Research and Practice
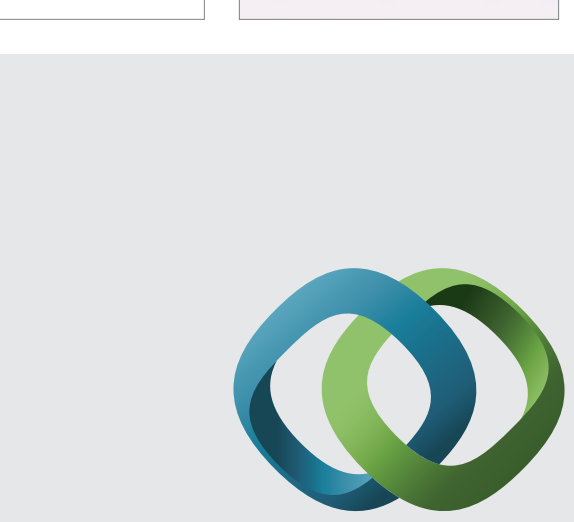

\section{Hindawi}

Submit your manuscripts at

http://www.hindawi.com
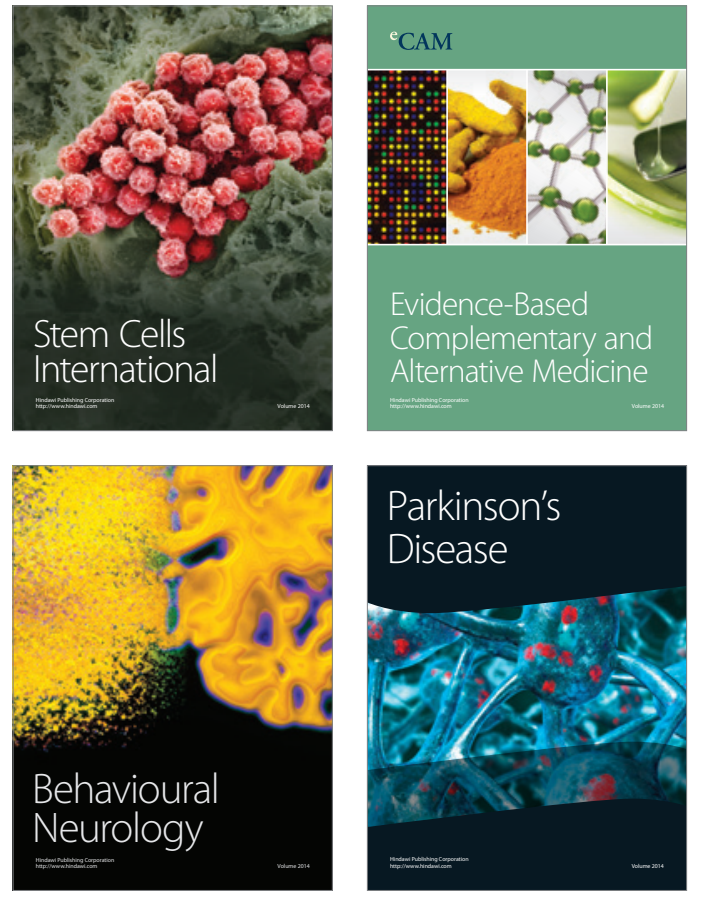
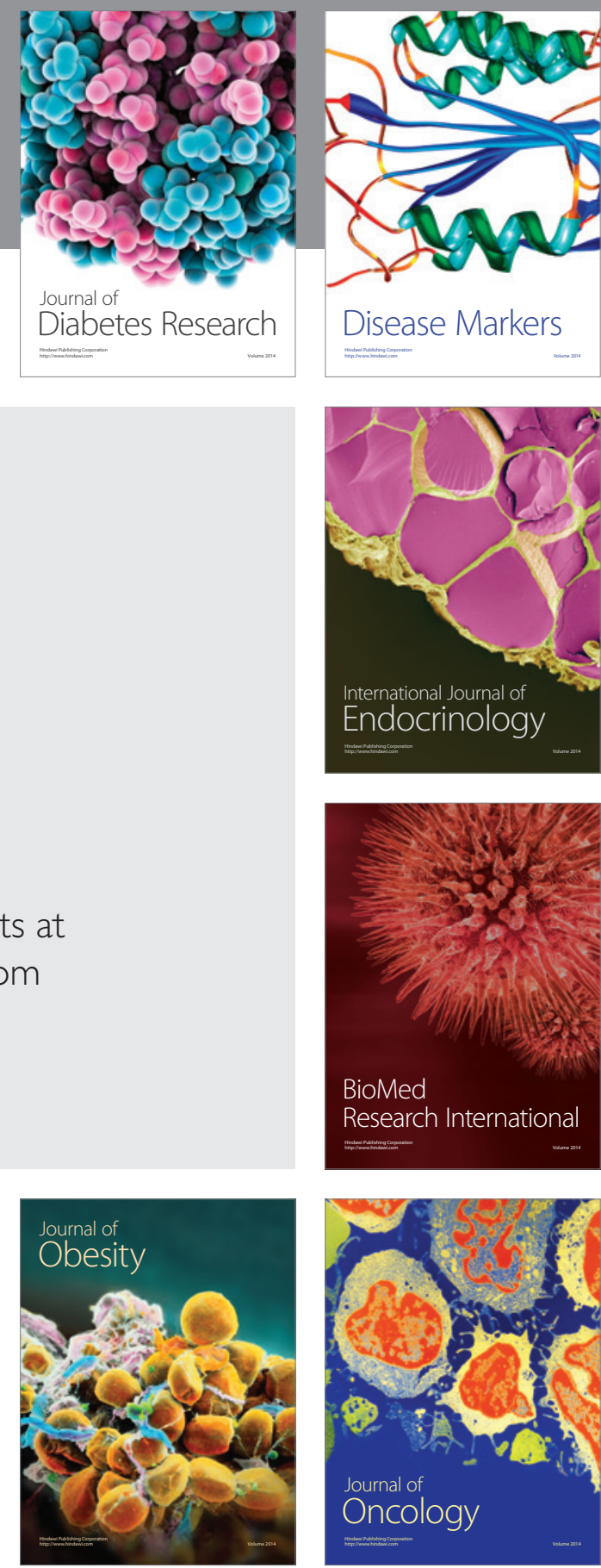

Disease Markers
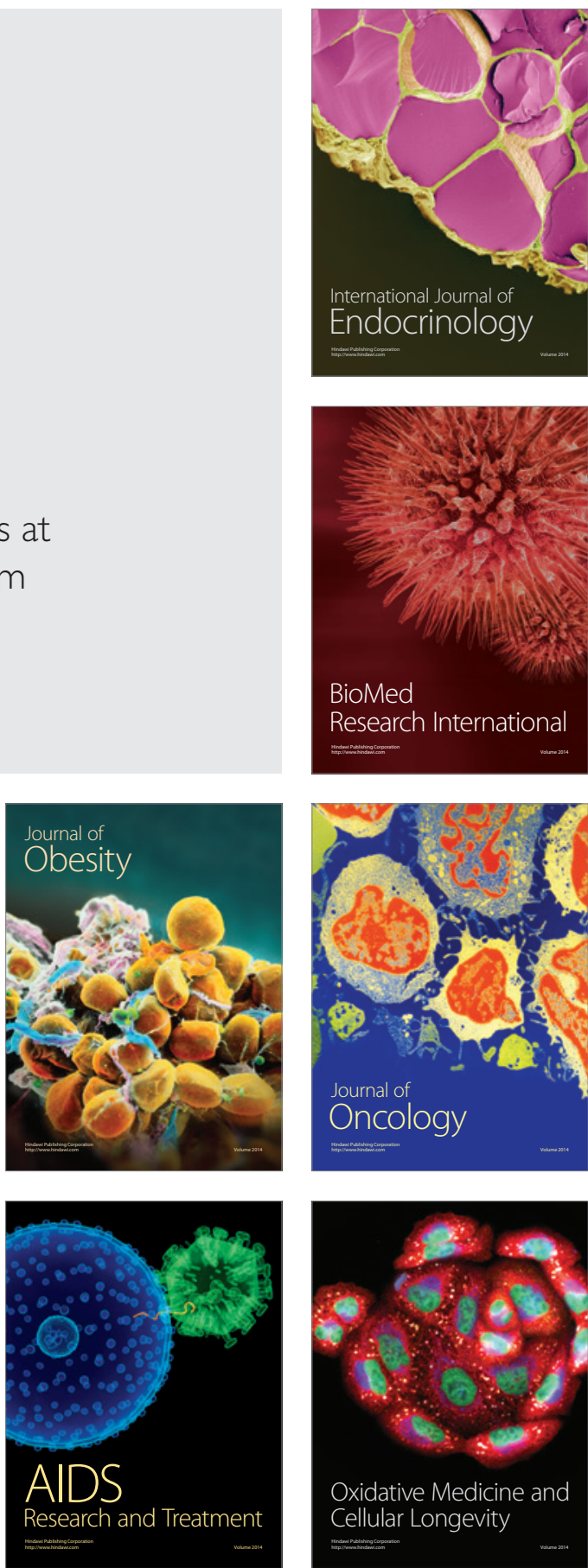